\title{
Early development and allometric growth in Nannacara anomala Regan, 1905 (Perciformes: Cichlidae) under laboratory conditions
}

\author{
Krzysztof Kupren ${ }^{1}$, Maja Prusińska ${ }^{2}$, Daniel Żarski ${ }^{1}$, Sławomir Krejszeff ${ }^{1}$ \\ and Dariusz Kucharczyk ${ }^{1}$
}

\begin{abstract}
Morphological development and allometric growth of laboratory reared Nannacara anomala were studied from hatching to the loss of larval characters and beginning of squamation (18 days post-hatching) at $26^{\circ} \mathrm{C}$. The mean total length (TL) of larvae and juveniles increased from $3.74 \mathrm{~mm}$ at hatching to $9.60 \mathrm{~mm}$ at metamorphosis. Morphogenesis and differentiation were most intense during the first week of development. During this period (TL interval $=3.74-4.84 \mathrm{~mm}$ ) there was an evident priority to enhance the feeding and swimming capabilities by promoting accelerated growth in the head and tail regions. Following this period, there was a major decrease in growth coefficients, indicating a change in growth priorities. Observations on the early development of Nannacara anomala confirmed the basic uniformity development of a substrate brooding cichlid.
\end{abstract}

Se realizó el estudio del desarrollo morfológico y crecimiento alométrico de Nannacara anomala criada en el laboratorio en la temperatura de $26^{\circ} \mathrm{C}$, entre la eclosión y la pérdida de todas las características de larva y el principio del proceso de escamación (a los 18 días de la eclosión). La total logitud media (TL) de larvas aumentó de 3,74 mm en eclosión a 9,60 mm en el momento de metamorfosis. La morfogénesis y la diferenciación fueron más intensos durante la primera semana del desarrollo. En este periodo (el intervalo $\mathrm{TL}=3,74-4,84$ ) se observó una gran prioridad en la mejora de habilidades de encontrar alimento y nadar al promover el crecimiento de la zona de la cabeza y la cola. Transcurrido este periodo se notó una importante bajada de los coeficientes del crecimiento lo que indica el cambio de prioridades de crecimiento de distintas partes del cuerpo. Las observaciones del desarrollo temprano de Nannacara anomala confirman las similitudes principales en el desarrollo de cíclidos criados en sustratos.

Key words: Ontogeny, Fish larvae, Morphological characteristics, Larval development, Substrate-brooder.

\section{Introduction}

Nannacara anomala Regan, 1905 is a small substratebrooding Neotropical cichlid belonging to the Cichlinae, a subfamily with more than 600 known species. This species is found in Guianan rivers from the Aruka river in Guyana east to the lower Marowijne river in Suriname. Nannacara anomala is often found on flooded savannas near the coast. The male grows to a length of about $5.6 \mathrm{~cm}$ while the female is somewhat smaller (Kullander, 2003). Males of this species form a dominance system with one alpha male and a number of beta males (Brick, 1998). The dominant male is usually larger and more colorful than the subdominant males, often showing metallic blue on the head and flanks. Mature males generally also possess elongated dorsal and anal fins. Females are yellow with a black band along the lateral line, but showing a checkerboard pattern when ready to spawn. Both sexes look similar as juveniles. During the process of egg fertilization after mating, the female is very aggressive towards the male. Females lay their eggs (up to 300 eggs) on a cleaned substrate, and hatching occurs after a period of 3-4 days. Both eggs and fry are guarded by the female (Linke \& Staeck, 1994).

Nannacara anomala is a popular species in the trade of freshwater ornamental fish, since it is attractive in appearance and behaviour, is undemanding in maintenance and easily bred. Although Nannacara anomala is frequently kept in aquaria, literature on their early development is scarce and limited to general information. Moreover, there are only few detailed descriptions of larval development of Neotropical cichlids (Jones, 1972; Martinez \& Murillo, 1987; Cabrera et

${ }^{1}$ Department of Lake and River Fisheries, University of Warmia and Mazury in Olsztyn, Oczapowskiego 5, 10-095 Olsztyn, Poland. krzysztof.kupren@uwm.edu.pl (KK),dauniel@o2.pl (DZ),s.krejszeff@wp.pl (SK), darekk56@gmail.com (DK)

${ }^{2}$ Department of Ichthyology. The Stanislaw Sakowicz Inland Fisheries Institute in Olsztyn, Oczapowskiego 10, Poland. maja@infish.com.pl 
al., 1988; Meijide \& Guerrero, 2000; Pandolfi et al., 2009; Korzelecka-Orkisz et al., 2012).

The present work is the first comprehensive description of morphological changes associated with an analysis of growth patterns during early ontogeny, not only for Nannacara anomala but also among all substrate brooding cichlids. The changes in functional development and body shape of young fish, especially during the few first days after hatching, lead to the formation of characteristic allometric growth patterns. Besides, the chronology of allometric changes is related to the chronology of important early life history events (Gisbert, 1999; Kupren et al., 2014). An analysis of larval growth provides insights into the behavior and ecology of larvae at different developmental stages and may be used in assessing phylogenetic relationship (Gisbert, 1999). Moreover, morphological features are a very useful indicator for the determination of optimal rearing conditions of young fish (Peña $\&$ Dumas, 2009). The aim of the present study was to describe the morphological development and allometric growth patterns for Nannacara anomala larvae reared under controlled conditions.

\section{Material and Methods}

The research focused on the larval development of Nannacara anomala. The study was carried out in the aquarium laboratory of the Department of Lakes and Rivers Fishery, at the University of Warmia and Mazury, Olsztyn, Poland, where voucher specimens are deposited (UWMN 2710).

Mature ready-to-spawn fish were selected from a broodstock tank and were placed in up to $120 \mathrm{~L}$ spawning aquariums containing a substrate in the form of stones and coconut shells. The water conditions were kept at $26 \pm 0.5^{\circ} \mathrm{C}$; $\mathrm{pH} 7.0 ; 2 \mathrm{GH}$ hardness and $6.5 \pm 0.4 \mathrm{mg} / \mathrm{L}$ dissolved oxygen. The photoperiod was maintained at $12 \mathrm{~L} / 12 \mathrm{D}$. The fish were fed with frozen Chaoborus and Chironomus larvae.

Eggs were obtained from two pairs of Nannacara anomala which spawned simultaneously. Immediately after activation, approximately 400 eggs were transferred with the substratum to which they were attached to $50 \mathrm{~L}$ glass tanks with the same water condition. After hatching, which took place at 4 days after fertilization, newly hatched larvae without malformations were placed in three $1 \mathrm{~L}$ glass rearing tanks ( 50 individuals per tank). Each tank was supplied separately with filtered water from a sprinkler. Mechanical and biological filtration was provided with an external filter (Fluval 405). The recirculation system used in the experiment was described in detail by Krejszeff et al. (2010). The larvae were fed three times a day ad libitum with freshly-hatched Artemia franciscana. The aquaria were cleaned twice daily and the wastes and the rest of the food was siphoned to provide optimal rearing conditions. The dissolved oxygen and ammonia contents were $>80 \%$ saturation and $<0.01 \mathrm{mg} \mathrm{L}^{-1}$, respectively.

From hatching until end of metamorphosis (18 days posthatch - DPH), random samples of 30 larvae were taken each day (10 individuals from each small tank) prior to feeding during the morning. These specimens were observed under an Olympus SZ40 zoom stereomicroscope, photographed with a digital camera (Olympus DP12) and measured using image analysis program (Olympus DP-Soft). No anaesthetics were used in order to avoid affecting the development process of the specimens (Massee et al., 1995). After measuring, the fish were returned to the same tanks from which they had been taken.

We documented easily recognizable developmental events for Nanmacara anomala reared under controlled conditions. These stages have been based on the instantaneous states of ontogeny, recognized as the characteristic moments in fish development (Balon, 1975a; Snyder \& Muth, 2004). The larval period was identified according to Kendall et al. (1984) as the period from hatching to attainment of complete fin ray counts and beginning of squamation. The examined groups of specimens were allocated to a specific development stage if at least $50 \%$ specimens from the group met the stage criteria (Gadomski, 1995).

On each digital photograph, several body proportions associated with feeding and locomotion were measured to the nearest $0.01 \mathrm{~mm}$. These measurements were: head length (HL), trunk length (TRL); tail (post-anal) length (TAL); eye diameter (ED); head depth (HD); body depth (BD); muscle height at anus level (MH); tail depth at the caudal peduncle level (TD) and total length (TL) (Peña \& Dumas, 2009) (Fig. 1). All measurements were taken along lines parallel or perpendicular to the horizontal axis of the body (Gisbert, 1999). Dead and abnormal specimens were excluded from the analysis. The yolk sac volume $\left(\mathrm{mm}^{3}\right)$ was calculated (until completed absorption) using the formula: $\mathrm{V}=1 / 6 * \gamma * 1 * \mathrm{~h}^{2}$ where $h$ is the minimum diameter and $l$ is the maximum diameter of the yolk sac mass (Blaxter \& Hempel, 1963).

\section{Data analysis}

Growth patterns during the early development were modeled by a power function of TL and the allometric patterns were described by the growth coefficient (i.e., power function exponent) in the equation $\mathrm{Y}=a \mathrm{X}^{b}$, where $\mathrm{Y}$ is the dependent variable (measured character) and $\mathrm{X}$ is the independent variable (TL), $a$ is the intercept and $b$ is the growth coefficient. When isometric growth occurred, $b=1$, allometric growth was positive when $b>1$ and negative when $b<1$.

In addition, linear regressions were performed on log-

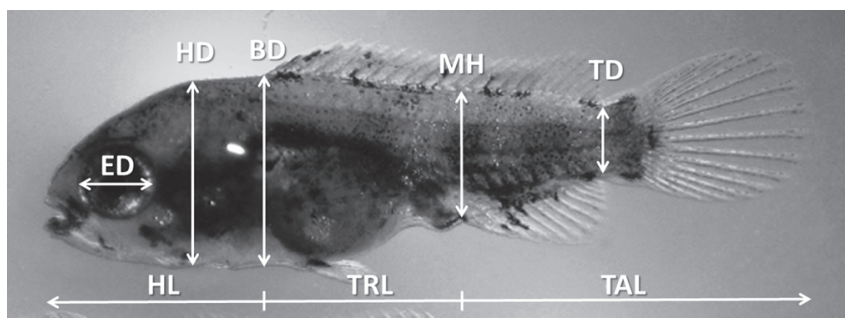

Fig. 1. Morphometric characters measured in Nannacara annomala. $\mathrm{BD}$, body depth; $\mathrm{ED}$, eye diameter; $\mathrm{HD}$, head depth; HL, head length; MH, musculature height; TAL, tail length; TD, tail depth; TL, total length and TRL, trunk length. 
transformed data (TL as independent variable) and the inflection points were calculated. Inflection points are the $\mathrm{X}$ values where the slope of growth changes. The inflection points were calculated according to van Snik et al. (1997). The $\mathrm{x}$-y data set was sorted according to increasing $\mathrm{x}$, being TL. Regression lines were calculated for $\mathrm{x}_{\min }$ until $\mathrm{x}_{\text {intermediate }}$, and for $\mathrm{x}_{\text {intermediate }}$ until $\mathrm{x}_{\max }, \mathrm{x}_{\text {intermediate }}$ varied iteratively from $\mathrm{x}_{\min }+2$ to $\mathrm{x}_{\max }-2$. Also, $t$ tests were performed to check whether the growth coefficients $\left(\mathrm{x}_{\min } \mathrm{x}_{\text {intermediate }}\right)$ and $\left(\mathrm{x}_{\text {intermediate }} \mathrm{x}_{\max }\right)$ differed significantly. The $\mathrm{x}_{\text {intermediate }}$ value that iteratively showed the largest $t$ was defined as the inflexion point.

\section{Results}

\section{Morphological development}

At hatching $(0 \mathrm{DPH})$, the larvae measured $3.74 \pm 0.07 \mathrm{~mm}$ (mean TL $\pm \mathrm{SD}$ ) and had the head slightly bent downwards with the three pairs of adhesive glands (two pairs situated on the parietal area, just above the eyes, third on the frontal region). The mouth was closed and the larvae had large yolk $\operatorname{sacs}\left(0.38 \pm 0.04 \mathrm{~mm}^{3}\right)$. The finfold covered the body from the dorsal area of the trunk to the ventral area of the yolk and was wider in the ventral part of the trunk and narrower in the dorsal region. Auditory capsules and otoliths were visible in the posterior head region. The digestive tract was an undifferentiated tube in the dorsal posterior region of the yolk sac. Melanophores were observed along the ventral part of the body and were scattered over the yolk sac. The eyes were not heavily pigmented. The notochord end was slightly flexed. An oval pectoral-fin bud was present. Larvae lay on the bottom attached to the substratum (Fig. 2a) and moved their tails rapidly. At $1 \mathrm{DPH}(3.92 \pm 0.07 \mathrm{~mm}$ TL$)$, the head was straightening, the mouth opened and ventilation movements were visible. The yolk sac had become smaller $(0.32 \pm 0.02$
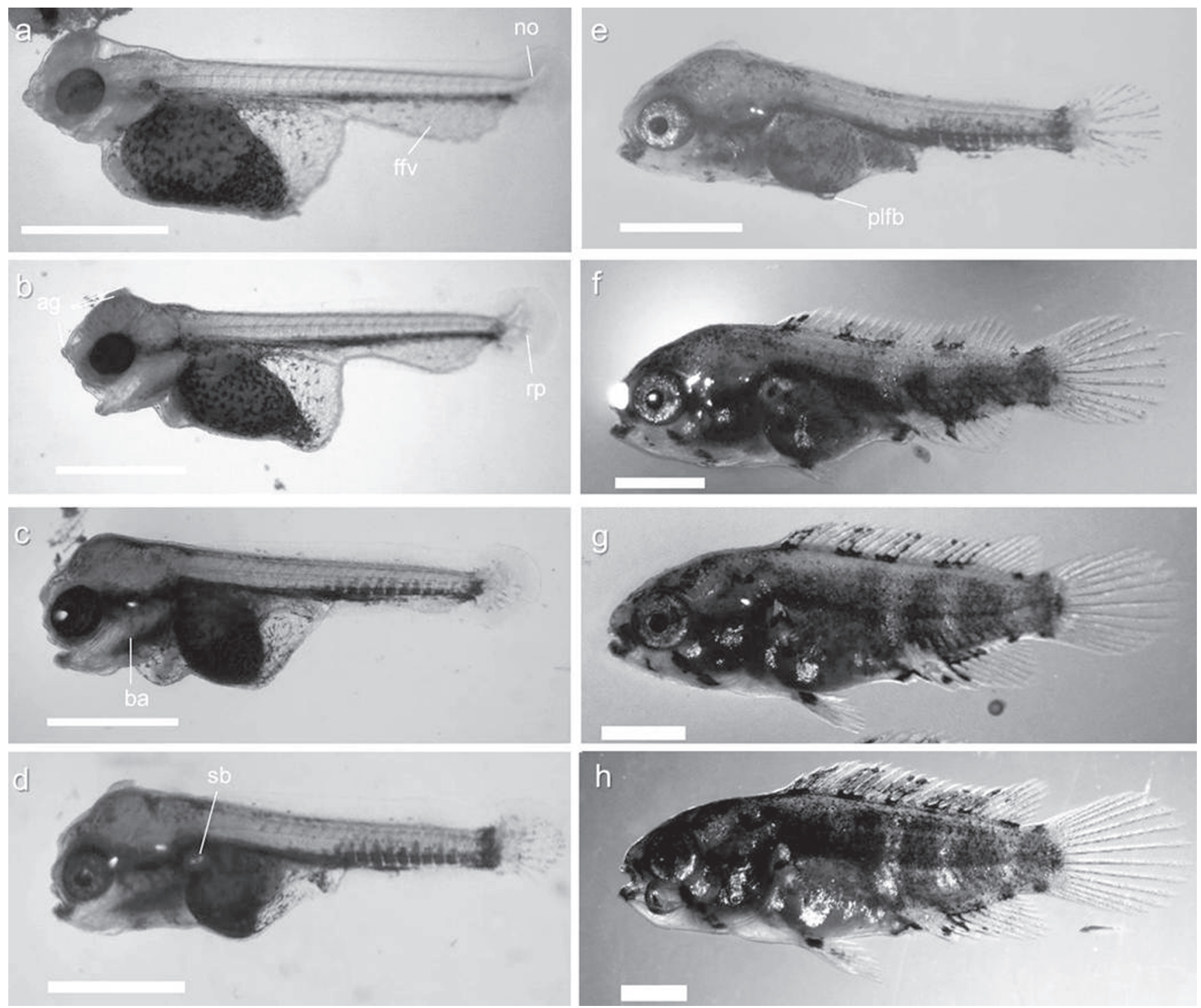

Fig. 2. Larval development of Nannacara annomala: (a) $0 \mathrm{DPH}$, days post hatch; (b) $1 \mathrm{DPH}$; (c) $2 \mathrm{DPH}$; (d) $3 \mathrm{DPH}$; (e) $5 \mathrm{DPH}$; (f) $7 \mathrm{DPH}$; (g) $10 \mathrm{DPH}$; (h) $15 \mathrm{DPH}$; (i) $18 \mathrm{DPH}$. Scale bars = $1 \mathrm{~mm}$. ag, adhesive glands; ba, branchial arches; ffv, finfold vessels; no, notochord; pfb, pelvic-fin bud; rp, rays primordia; sb, swim bladder. 
$\mathrm{mm}^{3}$ ). The notochord flexion was more obvious (about $45^{\circ}$ ) and rays primordia appeared on the ventral side of the caudal tip. The first stellate melanophores developed on the head and dorsal part of the trunk. The primordia of branchial arches were distinguished. Eyes fully pigmented (Fig. 2b).

At $2 \mathrm{DPH}(4.00 \pm 0.06 \mathrm{~mm}$ TL$)$, the process of notochord flexion was not finished. Caudal-fin rays were more developed and rays primordia appeared in the pectoral fin. Branchial arches were more differentiated and gill filaments had formed, but the reduced temporary embryonic respiratory system (respiratory plexuses present on the yolk sac and ventral finfold) were still visible (Fig. 2c). At 3 DPH $(4.11 \pm 0.08 \mathrm{~mm}$ TL) inflation of the swim bladder occurred. Larvae started to swim freely and feed exogenously, although the yolk sac was not totally resorbed $\left(0.03 \pm 0.001 \mathrm{~mm}^{3}\right)$. The process of notochord flexion was definitely finished. Head glands were regressing and losing functionality - disappearing completely during the following days (Fig. 2d).

At $4 \mathrm{DPH}(4.31 \pm 0.09 \mathrm{~mm} \mathrm{TL})$ most of the larvae completely resorbed the yolk sac and could actively swim. At $5 \mathrm{DPH}$ ( $4.41 \pm 0.15 \mathrm{~mm} \mathrm{TL})$, small pelvic fins buds were first observed (Fig. 2e). At $7 \mathrm{DPH}(4.96 \pm 0.28 \mathrm{~mm} \mathrm{TL})$ the first dorsal- and anal-fin rays appeared simultaneously (Fig. 2f). At $10 \mathrm{DPH}$ $(6.20 \pm 0.37 \mathrm{~mm} \mathrm{TL})$, pelvic-fin rays began to differentiate. Dorsal and anal fins were more developed. The number of melanophores had increased and started to be arranged along the trunk and tail dark blotches. Pigmentation on the fins was restricted to their base (Fig. 2g).
The finfold was completely absorbed at $15 \mathrm{DPH}(8.31 \pm$ $0.39 \mathrm{~mm} \mathrm{TL}$ ) and one day later (16 DPH, $8.88 \pm 0.39 \mathrm{~mm} \mathrm{TL})$ elongated anal and dorsal fins reached the end of caudal peduncle (Fig. 2h). On the last day of the experiment (18 DPH, $9.60 \pm 0.42 \mathrm{~mm}$ TL), scales covered most of the body. The fins were fully formed. The body was almost completely covered with melanophores and young fish were morphologically similar to the adults of this species (Fig. 2i). The main events during larval development of Nannacara anomala are summarized in Fig. 3.

\section{Allometric growth}

Growth of Nannacara anomala followed an exponential curve during the larval stage and is represented by the equation $\mathrm{y}=3.51 \mathrm{e}^{0.06 x}\left(\mathrm{R}^{2}=0.99, \mathrm{n}=447\right)$ where $\mathrm{y}$ is total length (mm) and $\mathrm{x}$ is DPH (Fig. 4).

The body proportions changed considerably during the larval period and early juveniles of Nannacara anomala. Inflection points for all the body measurements occurred between days 2 and 7, corresponding to the TL interval of 4.03 to $4.84 \mathrm{~mm}$ (Fig. 5), except for the TRL, which showed weak negative allometric growth $(b=0.86)$ throughout the studied period. In case of TAL, HL, ED, and HD there was a clear reduction in the growth coefficients after the inflection points from positive $(b=1.48,1.76,1.79$ and 3.13 , respectively, $\mathrm{P}<0.001)$ to near-isometric $(b=1.08,0.94,0.84$ and 0.91 , respectively) growth. Although positive allometric growth after inflexion point was still observed for the $\mathrm{MH}$ and $\mathrm{TD}$,

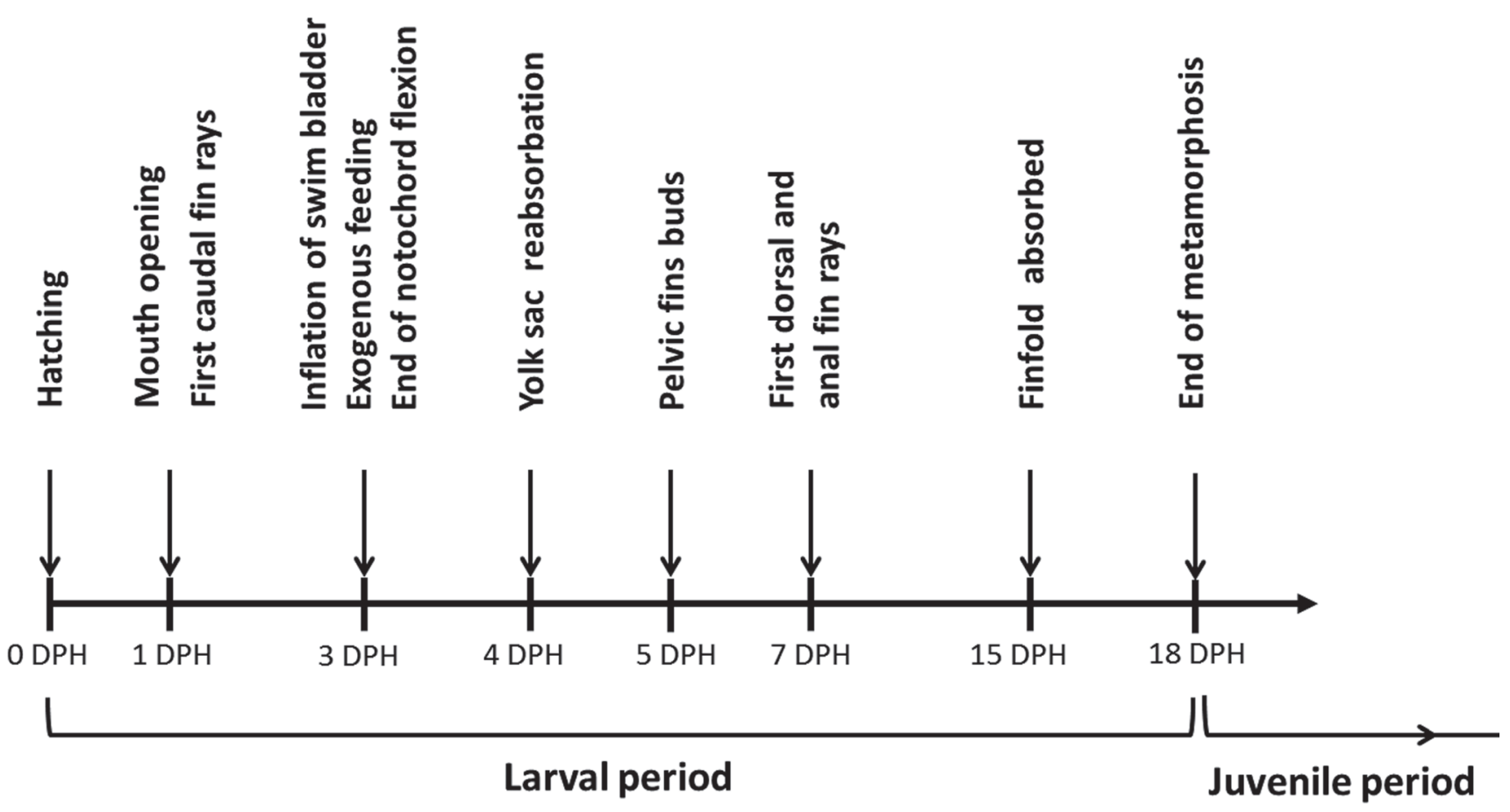

Fig. 3. Main events during larval development of the Nannacara annomala. DPH, days post hatch. 


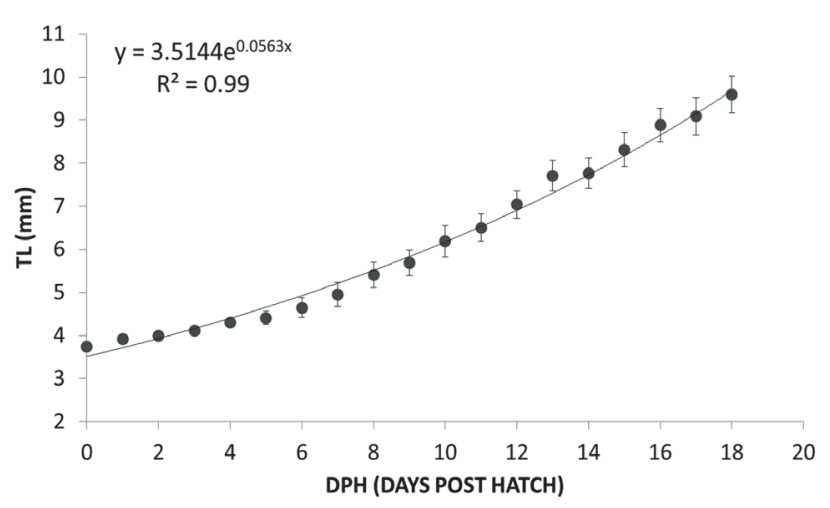

Fig. 4. Changes in total length (TL) from hatching to 18 days post hatch (DPH). Standard deviation (SD) represented by whiskers.

the value of growth coefficients were clearly lower ( $b$ changed from 2.67 to 1.98 end 4.12 to1.39, respectively, $\mathrm{P}<0.001$ ). Growth of the body depth (BD) showed the first negative ( $b$ $=-0.90)$ and near-isometric growth $(b=1.13)$ after the inflexion point.

\section{Discussion}

During the first days after hatching, the functional systems of Nannocara anomala larvae, as with most teleost species, were still incomplete and undeveloped. From hatching to day 3 , larvae lay in a hiding place and attached themselves to the substrate with a secretion from glands located on the head, while still with poorly developed fins and a large amount of endogenous yolk reserves. In this way, in the natural environment, the adhesive glands help prevent dispersion by currents and facilitate parental care (Meijide \& Guerrero, 2000; Korzelecka-Orkisz et al., 2012). During this time, respiration was accomplished mainly through the body surface and the network of vessels present on the yolk sac and ventral fin fold. These temporary structures are characteristic for many fish species that lay eggs in lentic water bodies (Balon, 1975a; Meijide \& Guerrero, 2000; Korzelecka-Orkisz et al., 2012) and have also been described in mouth-brooding species (Balon, 1975b, 1977; Holden \& Bruton, 1994; Prusiñska et al., 2009).

The observed changes in behavior, and swimming were linked to the development of nervous (midbrain and hindbrain), sensory (vision, olfaction), respiratory (branchial arches and filaments), feeding (functional jaw) and swimming (completion of notochord flexion and differentiation of primordial fin fold into unpaired fins) systems of the larvae. These rapid changes in functional development of Nannacara anomala larvae, when temporary embryonic organs are replaced by definitive ones, are characteristic for other substrate-brooding cichlids (Meijide \& Guerrero, 2000; Korzelecka-Orkisz et al., 2012) and also resulted in profound transformation of body shape. The most intense morphological and morphometric changes (inflexion points) observed in this study, occurred between day 2 and 7 after hatching and lay in a remarkably narrow range of total body lengths (4.03 - $4.84 \mathrm{~mm}$ ). Such cumulated changes in growth coefficients are also characteristic for few other teleost species which undergo rapid changes in swimming mode (from an anguilliform-type of locomotion to sub-carangiform swimming) during the flexion stage, when the caudal-fin rays appeared (van Snik et al., 1997; Gisbert et al., 2002; Peña \& Dumas, 2009). Most of the studied body parts of Nannacara anomala initially showed high positive growth. According to Osse \& van den Boogaart (2004), the positive allometry of head and tail regions, prior to the abdominal region during the endogenous nutrition period reflects the early priority to develop these structures and organs related to vital functions such as feeding and swimming. Such growth sequences could be also interpreted as an adaptation to reduce and optimize costs of larval transport (van Snik et al., 1997; Gisbert et al., 2002; Osse \& van den Boogaart, 2004). In older larvae and juvenile, all growth coefficients approach 1 (Fuiman, 1983). This change to isometry has been considered as a natural transition in growth priorities since primary functions have been fulfilled during the early developmental stages (Fuiman, 1983; Osse et al., 1997; van Snik et al., 1997). In Nannacara anomala larvae, near isometric growth after inflexion points were characteristic for most studied body regions. The positive allometry of the TD and MH throughout the rearing period contributes to increasing the swimming abilities of young Nannacara anomala (Cunha \& Planas, 1999).

The developmental stages and course of morphological changes reported in this study are in accordance with the morphological description of other Neotropical substrate brooding cichlids such as Cichlasoma dimerus (Meijide \& Guerrero, 2000) and Pterophyllum scalare. (Korzelecka-Orkisz et al., 2012). However, the total length at each developmental stage (e.g., mouth opening, swim bladder inflation or unpaired fin differentiation) differs between these species. Generally, Nannacara anomala reached all developmental stages earlier at a smaller body size than Cichlasoma dimerus and Pterophyllum scalare. For example, inflation of the swim bladder in Nannacara anomala takes place at $3 \mathrm{DPH}$, when the larvae had an average total length of $4.11 \mathrm{~mm}$. In Cichlasoma dimerus and Pterophyllum scalare, this stage was reached 2 days later with a total body length near $5.5 \mathrm{~mm}$. The differences can be partly explained by the size of the mature fish (adult Cichlasoma and Pterophyllum are at least two times longer than Nannacara) and the rearing conditions (i.e., temperature and feeding schedule).

Especially typical for substrate brooding cichlids is an early start and rapid progress in notochord flexion. The first caudalfin rays appear soon after hatching (1-2 DPH) before complete resorption of the yolk sac (Meijide \& Guerrero, 2000; KorzeleckaOrkisz et al., 2012). Different patterns of development are characteristic for fish of two other ethological sections: nonguarders and bearers (according to Balon, 1975b). In nonguarders, producing large numbers of small eggs (e.g., lithopelagophils), the flexion of the notochord and the 
appearance of rays in the caudal fin take place after definite resorption of the yolk sac. In the case of bearers, which usually lay few large eggs (mouth-brooders cichlids) yolk sac resorption occurs relatively late. During endogenous feeding the rays appear in all fins (Fujimura \& Okada, 2007; Kupren et al., 2014).

In conclusion, the transition of Nannacara anomala from larvae to juvenile progresses very rapidly (within 18 days). Most of the important developmental events were observed
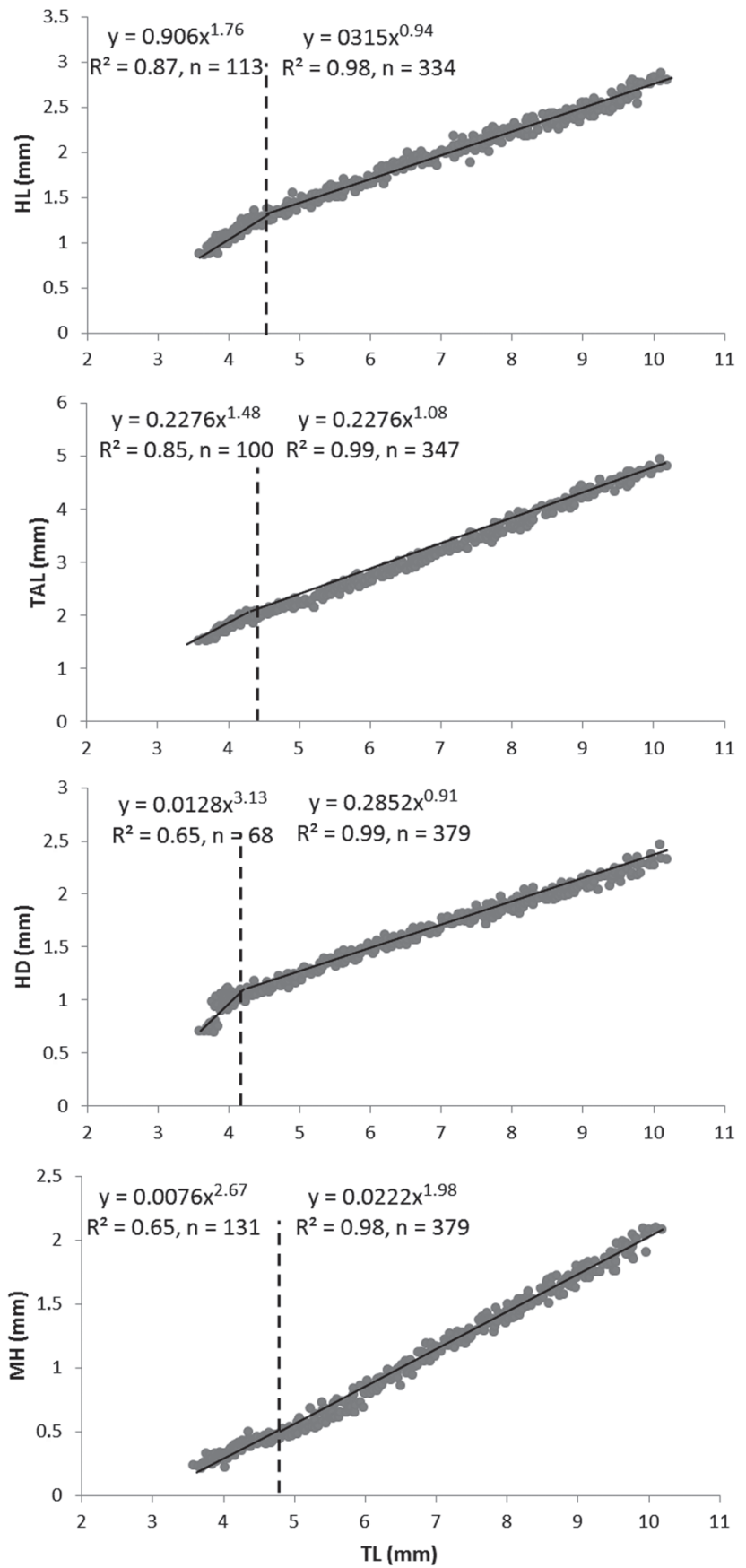

during endogenous feeding. At the end of this period (4 DPH), Nannacara anomala was capable of catching prey and free swimming. This was possible mainly due to the opening of the mouth, the filling of the swim bladder and the appearance of the caudal and pectoral fin rays. Subsequent morphological changes (fin differentiation) and the growth priorities led to a further improvement in swimming skills, which increased the survival chances of young fish.
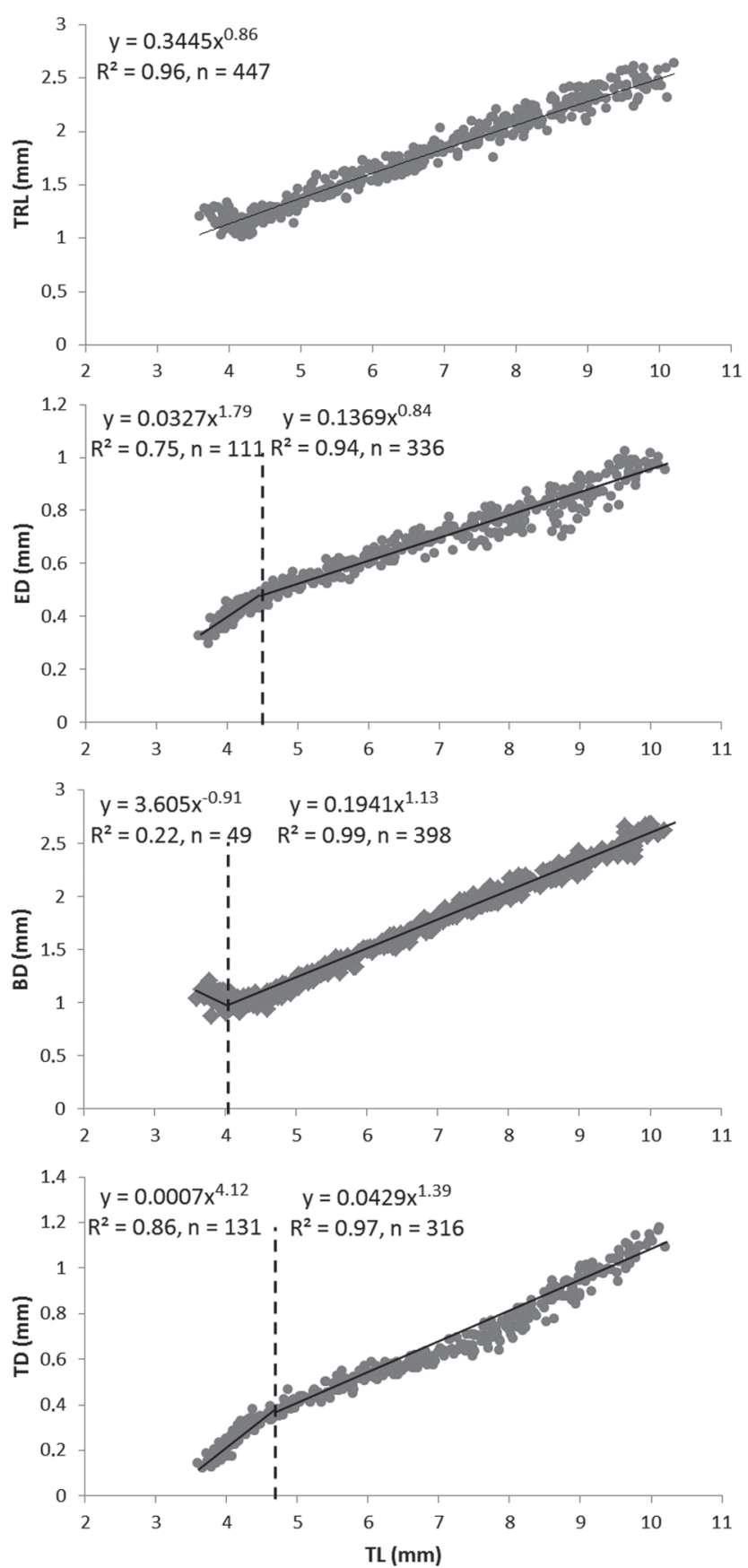

Fig. 5. Allometric growth equations between measured body proportions and total length during Nannacara anomala development. BD, body depth; ED, eye diameter; HD, head depth; HL, head length; MH, musculature height; TAL, tail length; TD, tail depth; TL, total length and TRL, trunk length. The dashed line represents the inflection point of growth. 


\section{Literature Cited}

Balon, E. K. 1975a. Terminology of intervals in fish development. Journal of the Fisheries Research Board of Canada, 32: 1663 1670.

Balon, E. K. 1975b. Reproductive guilds of fishes: a proposal and defnition. Journal of the Fisheries Research Board of Canada, 32: 821-864.

Balon, E. K. 1977. Early ontogeny of Labeotropheus Ahl, 1927 (Mbuna, Cichlidae, Lake Malawi), with a discussion on advanced protective styles in fish reproduction and development. Environmental Biology of Fishes, 2: 147-176.

Blaxter, J. \& G. Hempel. 1963. The influence of egg size on herring larvae (Clupea harengus L.). Journal du Conseil Permanent International pour l'Exploration de la Mer, 28: 211-240.

Brick, O. 1998. Fighting behaviour, vigilance and predation risk in the cichlid fish Nannacara anomala. Animal Behaviour, 56: 309-317.

Cabrera, J., R. Murillo \& M. Mora. 1988. Desarrollo embrionario, larval y del alevin de Cichlasoma dovii (Günther, 1864) (Pisces: Cichlidae). Revista de Biología Tropical, 36: 417-422.

Cunha, I. \& M. Planas. 1999. Optimal prey size for early turbot larvae (Scophthalmus maximus L.) based on mouth and ingested prey size. Aquaculture, 175: 103-110.

Fuiman, L. A. 1983. Growth gradients in fish larvae. Journal of Fish Biology, 23:117-123.

Fujimura, K. \& N. Okada. 2007. Development of the embryo, larva and early juvenile of Nile tilapia Oreochromis niloticus (Pisces: Cichlidae). Developmental staging system. Development, Growth \& Differentiation, 49: 301-324.

Gadomski, D. M. 1995. Effects on temperature on the development and survival of eggs of four coastal California fishes. Fishery Bulletin, 94: 41-48.

Gisbert, E. 1999. Early development and allometric growth patterns in Siberian sturgeon and their ecological significance. Journal of Fish Biology 54: 852-862.

Gisbert, E., G. Merino, J. B. Muguet, D. Bush, R. H. Piedrahita \& D. E. Conklin. 2002. Morphological development and allometric growth patterns in hatchery-reared California halibut larvae. Journal of Fish Biology, 61: 1217-1229.

Holden, K. K. \& M. N. Bruton. 1994. The early ontogeny of the southern mouthbrooder, Pseudocrenilabrus philander (Pisces, Cichlidae). Environmental Biology of Fishes, 41: 311-329.

Jones, A. J. 1972. The early development of substrate-brooding cichlids (Teleostei: Cichlidae) with a discussion of a new systemof staging. Journal of Morphology, 136: 255-272.

Kendall, A. W., E. H. Ahlstrom \& H. G. Moser. 1984. Early life history stages of fishes and their characters. Pp. 11-22. In: Moser, H. G., W. J. Richards, D. M., Cohen, M. P. Fahay, A. W. Kendall \& S. L. Richardson (Eds.). Ontogeny and systematics of fishes: American Society of Ichthyologists and Herpetologists, Special Publication No. 1. Allen Press Inc, Lawrence, KS,

Korzelecka-Orkisz A., Z. Szalast, D. Pawlos, I. Smaruj, A. Tañski, J. Szulc \& K. Formicki. 2012. Early ontogenesis of the angelfish, Pterophyllum scalare Schultze, 1823 (Cichlidae) Neotropical Ichthyology, 10: 567-576.
Krejszeff, S., D. ${ }^{-}$arski, D. Kucharczyk, K. Kupren, K. Targoñska \& A. Mamcarz. 2010. An experimental device for egg incubation and fish larvae rearing under laboratory conditions. Polish Journal of Natural Sciences, 25: 190-199.

Kullander, S. O. 2003. Cichlidae. Pp. 605-654. In: Reis, R. E., S. O. Kullander \& C. J. Ferraris, Jr. (Eds.). Check list of the freshwater fishes of South and Central America. Edipucrs, Porto Alegre.

Kupren, K., I. Tr'bska, D. ${ }^{-}$arski, S. Krejszeff, K. Palinska- ${ }^{-}$arska \& D. Kucharczyk. 2014. Early development and allometric growth patterns in burbot Lota lota L. Aquaculture International, 22: 29-39.

Linke, H. \& W. Staeck. 1994. The American Cichlids, Dwarf Cichlids: A Handbook for Their Identification, Maintenance and Breeding. Tetra Verlag, Germany.

Martinez, G. \& R. Murillo. 1987. Desarrollo larval de Cichlasoma nigrofasciatum (Günther, 1868) (Pisces: Cichlidae) en cultivos de laboratorio. Revista de Biología Tropical, 35: 113-119.

Massee, K. C., M. B. Rust, R. W. Hardy \& R. R. Stickney. 1995. The effectiveness of tricaine, quinaldine sulfate and metomidate as anestethics for larval fish. Aquaculture, 134: 351-359.

Meijide, F. J. \& G. A. Guerrero. 2000. Embryonic and larval development of a substrate-brooding cichlid Cichlasoma dimerus (Heckel, 1840) under laboratory conditions. Journal of Zoology, London, 252: 481-493.

Osse, J. W. \& J. G. M. van den Boogaart. 2004. Allometric growth in Fish Larvae: Timing and Function. Pp. 167-194. In: J. J. Govoni (Ed.). The Development of Form and Function in Fishes and the Question of Larval Adaptation, American Fisheries Society, Symposium 40, Bethesda, Maryland.

Osse, J. W., J. G. M. van den Boogaart, G. M. J. van Snik \& L. van der Sluys. 1997. Priorities during early growth of fish larvae. Aquaculture, 155: 249-258.

Pandolfi, M. M., M. Cánepa, F. J. Meijide, F. Alonso, G. R. Vázquez, M. C. Maggese \& P. G. Vissio. 2009. Studies on the reproductive and developmental biology of Cichlasoma dimerus (Percifomes, Cichlidae). Biocell, 33:1-18

Peña, R. \& S. Dumas. 2009. Development and allometric growth patterns during early larval stages of the spotted sand bass Paralabrax maculatofasciatus (Percoidei: Serranidae). Scientia Marina, 73S1: 183-189.

Prusiñska, M., A. Mamcarz \& K. Kupren. 2009. Early ontogeny of Tropheus moorii (Pisces, Cichlidae, Lake Tanganika) in laboratory conditions. Polish Journal of Natural Sciences, 23: 888-903.

van Snik, G. M. J., J. G. M. van den Boogaart \& W. M. Osse. 1997. Larval growth patterns in Cyprinus carpio and Clarias gariepinus with attention to the finfold. Journal of Fish Biology, 50: 1339-1352.

Snyder, D. E. \& R. T. Muth. 2004. Catostomid fish larvae and early juveniles of the Upper Colorado River Basin - morphological descriptions, comparisons, and computerinteractive key. Colorado Division of Wildlife Technical Publication 42.

Submitted March 28, 2013 Accepted March 21, 2014 by George Mattox Published September 30, 2014 